\title{
REFLEXIONES EN TORNO A LAS MODIFICACIONES PARA SANCIONAR EL FEMICIDIO Y OTRAS REFORMAS RELACIONADAS (LEY N² 20.480)
}

\author{
REFLECTIONS ON THE MODIFICATIONS FOR SANCTIONING \\ FEMICIDE AND OTHER RELATED REFORMS (ACT N 20.480)
}

\section{MARÍA ElENA SANTIBÁÑEZ TORRES* TATIANA VARGAS PINTO**}

\section{INTRODUCCIÓN}

\subsection{ConteXto DE La ReForma}

Para examinar las reformas que se introducen es necesario explicar su contexto. Este se caracteriza por la evidente preocupación actual por conductas violentas contra la mujer, especialmente cuando tienen lugar dentro de la familia. Allí, la relación de familiaridad, confianza y "amor" entre víctima y victimario tiende a agravar la situación de agresión. Cuando las cifras muestran que una de las principales causas de muerte de la mujer en el mundo es la violencia intrafamiliar, como lo hace el último informe de la OMS (Organización Mundial de la Salud), "Las mujeres y la salud: los datos de hoy, la agenda de mañana" ${ }^{1}$ se constata un problema grave que exige respuestas. En este sentido, Chile tiene una legislación que regula la violencia en el ámbito familiar, Ley $\mathrm{N}^{\circ} 20.066$, de violencia intrafamiliar ${ }^{2}$, sin distinguir diferencias penológicas respecto de la que se dirige específicamente contra la mujer. Así, no se prevé una mayor pena para la muerte de la mujer víctima de su pareja ni se contemplan supuestos específicos en los que la mujer es víctima.

* Abogada. Profesora de Derecho Penal y Derecho Procesal Penal de la Pontificia Universidad Católica de Chile.

** Abogada. Profesora de Derecho Penal de la Universidad de los Andes.

${ }^{1}$ Resulta interesante observar que la violencia aumenta en los países de mayores ingresos. Ver WHO, Women and health. Today's evidence tomorrow's agenda, 2009, pp. 39, 40, 55 y 56.

${ }^{2}$ En adelante, Ley de VIF.
La regulación vigente hasta antes de la entrada en vigencia de la ley que se comenta parecía solo considerar el contexto familiar y no la condición de mujer. Las agresiones entre personas especialmente vinculadas, familiares, que recaían en la mujer por el hecho de ser tal, podría decirse que consideraban una "doble debilidad" dada por la condición de mujer del sujeto pasivo - sin perjuicio de que esta calidad no determina per se un estado más débil- y su vínculo con el agente, la familiaridad. En todo caso, a partir de la Ley de VIF se observó cierta preocupación por la adopción de políticas preventivas y asistenciales respecto de la violencia contra la mujer y los niños (art. 3) ${ }^{3}$.

${ }^{3}$ Art. 3. "Prevención y Asistencia. El Estado adoptará políticas orientadas a prevenir la violencia intrafamiliar, en especial contra la mujer, los adultos mayores y los niños, y a prestar asistencia a las víctimas.

Entre otras medidas, implementará las siguientes:

a) Incorporar en los planes y programas de estudio contenidos dirigidos a modificar las conductas que favorecen, estimulan o perpetúan la violencia intrafamiliar;

b) Desarrollar planes de capacitación para los funcionarios públicos que intervengan en la aplicación de esta ley;

c) Desarrollar políticas y programas de seguridad pública para prevenir y erradicar la violencia intrafamiliar;

d) Favorecer iniciativas de la sociedad civil para el logro de los objetivos de esta ley;

e) Adoptar las medidas necesarias para dar cumplimiento a la Convención Interamericana para Prevenir, Sancionar y Erradicar la Violencia contra la Mujer, la Convención sobre los Derechos del Niño 
Las estadísticas chilenas del SERNAM (Servicio Nacional de la Mujer), así como los datos de la OMS y el nuevo Informe de Desarrollo Humano en Chile de 2010 de la PNUD (Programa de las Naciones Unidas para el Desarrollo), muestran un aumento de la violencia contra la mujer, específicamente del llamado "femicidio" 4, como expresión máxima de agresión en su contra ${ }^{5}$. Esto motivó campañas que plantearon la necesidad de crear en la legislación chilena un tipo penal especial que lo castigue.

Hasta la fecha de publicación de la ley en comento, las agresiones en contra de la mujer se sancionaban normalmente como delitos comunes de lesiones y homicidios. Las únicas reglas especiales tenían que ver con la consideración del contexto intrafamiliar, según el artículo $5^{\circ}$ de la Ley de $\mathrm{VIF}^{6}$, que en general

y demás instrumentos internacionales suscritos por el Estado de Chile, y

f) Crear y mantener sistemas de información y registros estadísticos en relación con la violencia intrafamiliar".

${ }^{4}$ El término femicidio fue utilizado por la ONU a partir del año 2001 para referirse al asesinato de mujeres como resultado extremo de la violencia de género que ocurre tanto en el ámbito privado como en el espacio público.

5 Hasta diciembre de 2009 se registraron 55 femicidios; mientras que hasta el 1 de diciembre de 2010 aparecen 41. http://www.sernam.cl/portal/ index.php/femicidios2009; http://www.sernam.cl/ portal/index.php/femicidios2010. Respecto al aumento del femicidio véase también http:// www.who.int/mediacentre/factsheets/fs239/es/ index.htm y el informe de la PNUD, Desarrollo Humano en Chile 2010. Género: Los desafíos de la igualdad, Ograma impresión, Santiago, 2010, pp. 98 y 99.

${ }^{6}$ Art. $5^{\circ}$ : "Será constitutivo de violencia intrafamiliar todo maltrato que afecte la vida o la integridad física o psíquica de quien tenga o haya tenido la calidad de cónyuge del ofensor o una relación de convivencia con él; o sea pariente por consanguinidad o por afinidad en toda la línea recta o en la colateral hasta el tercer grado inclusive, del ofensor o de su cónyuge o de su actual conviviente.

También habrá violencia intrafamiliar cuando la conducta referida en el inciso precedente ocurra entre los padres de un hijo común, o recaiga sobre funciona como agravante de responsabilidad para los tipos de lesiones y para el parricidio. Esta misma ley creó el delito de "maltrato habitual” (artículo 14)7 , estableció límites y agravantes para las lesiones y amplió los sujetos a los que se aplica el parricidio, al incorporar al conviviente ${ }^{8}$. Así se plasmó una idea amplia de familia 9 , pero nada se dijo de la calidad de mujer. Quizá, no era el momento o la instancia para hacerlo. La Ley de VIF tenía que preocuparse por agresiones dentro de ese ámbito. La consideración de la mujer permitiría

persona menor de edad o discapacitada que se encuentre bajo el cuidado o dependencia de cualquiera de los integrantes del grupo familiar".

7 Art. 14. "Delito de maltrato habitual. El ejercicio habitual de violencia física o psíquica respecto de alguna de las personas referidas en el artículo $5^{\circ} \mathrm{de}$ esta ley se sancionará con la pena de presidio menor en su grado mínimo, salvo que el hecho sea constitutivo de un delito de mayor gravedad, caso en el cual se aplicará solo la pena asignada por la ley a este.

Para apreciar la habitualidad, se atenderá al número de actos ejecutados, así como a la proximidad temporal de los mismos, con independencia de que dicha violencia se haya ejercido sobre la misma o diferente víctima. Para estos efectos, no se considerarán los hechos anteriores respecto de los cuales haya recaído sentencia penal absolutoria o condenatoria.

El Ministerio Público solo podrá dar inicio a la investigación por el delito tipificado en el inciso primero, si el respectivo Juzgado de Familia le ha remitido los antecedentes, en conformidad con lo dispuesto en el artículo 90 de la ley $\mathrm{N}^{\circ} 19.968$ ".

8 El art. 21 letras d y c de la Ley de VIF dispone que las violencias dentro de un contexto intrafamiliar nunca pueden calificarse como delito-falta de lesiones leves (art. $494 \mathrm{~N}^{\circ} 5$ CP.) y en caso del delito de lesiones el contexto funciona como agravante (art. 400). Por su parte, el art. 25 de esa ley incorpora en el parricidio al conviviente como nuevo sujeto (art. 390 CP.), ampliando los supuestos sancionados por la pena más dura que hoy contempla nuestro Código Penal.

${ }^{9} \mathrm{La}$ modificación fue reflejo de la actual noción de familia, que se amplía más allá del vínculo conyugal. En este sentido véase VAN WeEZEL, Alex (2008) "Lesiones y violencia intrafamiliar". Revista Chilena de Derecho. Vol. 35: pp. 223-225. 
críticas como la que sostuvo Maqueda Abreu $^{10}$, aunque a la inversa, a la Ley de violencia de género, por la ampliación de sujetos fuera del género. Resulta más adecuado hacerlo en una regulación particular o en la forma específica que lo hizo la Ley No 20.480 .

Por último, la creación de un tipo penal especial de femicidio, con un nomen iuris propio, busca llamar la atención a la ciudadanía sobre el fenómeno, permitiendo que las estadísticas de los distintos organismos encargados de levantarlas puedan reflejar claramente el número de homicidios cometidos contra mujeres que son o han sido cónyuges o convivientes del agresor. Esta medida busca evitar que esas muertes se incorporen a las estadísticas totales de los parricidios que se ejecutan, logrando con ello poner en evidencia el problema ante la sociedad y adoptar políticas específicas de prevención y represión.

\section{2. ANTECEDENTES Y DISCUSIÓN LEGAL}

La omisión de la condición especial de la mujer, particularmente en el entorno familiar, explica la ley que se comenta, que fue precedida por varios otros proyectos. La preocupación por un tipo de "femicidio" se propone ya el 3 de abril de 2007, Boletín $\mathrm{N}^{\circ}$ 4937-18. Ese mismo año se pretende establecer nuevas agravantes (Boletín $N^{\circ}$ 5472-07) y modificar ciertos procedimientos y medidas vinculadas con la violencia contra la mujer (Boletín $N^{\circ}$ 5450-07 de 31 de octubre, Boletín $\mathrm{N}^{\circ}$ 5568-07 de 13 de diciembre y el mismo proyecto de 3 de abril).

El proyecto definitivo reúne los Boletines $\mathrm{N}^{\circ}$ s. 4937-18 y 5308-18, que se refunden para modificar tres cuerpos legales: el Código Penal, la Ley de Violencia Intrafamiliar y la Ley que crea los Tribunales de Familia. El núcleo de la reforma supone la introducción del femicidio en el Código Penal, aunque, como

\footnotetext{
10 Maqueda Abreu, María Luisa, "La violencia contra las mujeres: Una revisión crítica de la Ley integral", 2006, http://webs.uvigo.es/pmayobre/06/ arch/profesorado/inma_valeije/ley_integral.doc, pp. 4-6, estima que lo criticable es que venga de una ley que se refiere únicamente a la violencia de género.
}

se verá, se incorporan allí otras importantes modificaciones.

Los alcances para la Ley de VIF se comprenden porque es en este ámbito intrafamiliar donde se producen las agresiones más relevantes hacia la mujer y, especialmente, por la propia referencia a la prevención y asistencia de la mujer afectada por esta clase de violencia, como políticas. Contempla medidas que el Estado debe adoptar, entre otras, las necesarias para dar cumplimiento a la Convención Interamericana para Prevenir, Sancionar y Erradicar la Violencia contra la Mujer, la Convención sobre los Derechos del Niño y demás instrumentos internacionales suscritos. Asimismo, encarga al Servicio Nacional de la $\mathrm{Mu}-$ jer (SERNAM) orientar en las políticas públicas vinculadas con la protección de la mujer en este ámbito (artículo $4^{\circ 11}$ ). Todo ello se potencia o refuerza con las medidas de protección y resguardo que se disponen en caso de una "situación de riesgo inminente", con el solo mérito de la denuncia, sobre todo frente a la cautela especial de la víctima embarazada (artículo $7^{12}$ ). Justamente, una de las preocu-

${ }^{11}$ Art. 40. "Corresponderá al Servicio Nacional de la Mujer proponer al Presidente de la República las políticas públicas para el cumplimiento de los objetivos de esta ley.

En coordinación y colaboración con los organismos públicos y privados pertinentes formulará anualmente un plan nacional de acción.

Para los efectos de los incisos anteriores, el Servicio Nacional de la Mujer tendrá las siguientes funciones:

a) Impulsar, coordinar y evaluar las políticas gubernamentales en contra de la violencia intrafamiliar;

b) Recomendar la adopción de medidas legales, reglamentarias o de otra naturaleza para prevenir, sancionar y erradicar la violencia intrafamiliar;

c) Prestar asistencia técnica a los organismos que intervengan en la aplicación de esta ley que así lo requieran, y

d) Promover la contribución de los medios de comunicación para erradicar la violencia contra la mujer y realzar el respeto a su dignidad".

12 Art. $7^{\circ}$. "Situación de riesgo. Cuando exista una situación de riesgo inminente para una o más personas de sufrir un maltrato constitutivo de violencia intrafamiliar, aun cuando este no se haya lleva- 
paciones de este proyecto se vincula con la aplicación de medidas cautelares útiles para mujeres víctimas de violencia intrafamiliar. Estas consideraciones también explican la reforma a la ley que crea los Tribunales de Familia.

El estudio de las conductas de maltrato a la mujer en el seno familiar cobra especial relevancia para hacer frente al "femicidio" y las exigencias internacionales, ya provengan de tratados o de la propia regulación interna de cada país. Desde esta perspectiva, la legislación española aparece como una de las más avanzadas de Europa, principalmente a partir de la Ley Orgánica 3/1989³.

do a cabo, el tribunal, con el solo mérito de la denuncia, deberá adoptar las medidas de protección o cautelares que correspondan.

Se presumirá que existe una situación de riesgo inminente como la descrita en el inciso anterior cuando haya precedido intimidación de causar daño por parte del ofensor o cuando concurran además, respecto de este, circunstancias o antecedentes tales como: drogadicción, alcoholismo, una o más denuncias por violencia intrafamiliar, condena previa por violencia intrafamiliar, procesos pendientes o condenas previas por crimen o simple delito contra las personas o por alguno de los delitos establecidos en los párrafos 5 y 6 del Título VII, del Libro Segundo del Código Penal o por infracción a la ley $\mathrm{N}^{\circ} 17.798$, o antecedentes psiquiátricos o psicológicos que denoten características de personalidad violenta.

Además, el tribunal cautelará especialmente los casos en que la víctima esté embarazada, se trate de una persona con discapacidad o tenga una condición que la haga vulnerable".

13 A raíz de la promulgación del nuevo Código Penal de 1995, la tutela jurídica de la mujer maltratada se ha visto reforzada por sucesivas modificaciones legislativas (LO 14/1999, LO 11/2003, LO 15/ 2003, LO 1/2004), específicamente la Ley Orgánica 1/2004 de Medidas de Protección Integral contra la Violencia de Género. Esta regulación se acompaña de la reforma de la Ley de Enjuiciamiento Criminal; de la creación de Juzgados y Fiscalía de Violencia contra la mujer; al igual que la creación del Observatorio Estatal de Violencia sobre la Mujer. Ello además se complementa con instrucciones $(4 / 2004,2 / 2005)$ y Circulares $(3 / 2003,4 /$ 2003) del Ministerio Fiscal que unifican su actuación como Ministerio Público.

\section{ANÁLISIS DE LA LEY Nº 20.480}

La principal idea de la ley es el reconocimiento de una situación de violencia particularmente grave que se dirige a una mujer por el solo hecho de ser tal, aunque se ubica de todas formas dentro del contexto intrafamiliar. Así, se establece finalmente el llamado "femicidio" en la legislación nacional actual, justo luego de celebrar el "Bicentenario de la República”. Como se expuso, el legislador va más allá de esta introducción y busca una protección integral de la mujer, que suma aspectos regulados en la Ley de VIF y en la que crea los Tribunales de Familia. Las reformas se extienden incluso a situaciones de riesgo general, específicamente al incorporar una nueva causa de exención de responsabilidad penal en la parte general del Código Penal. A continuación, procede examinar estas modificaciones.

\section{1. MODIFICACIONES INTRODUCIDAS AL CÓdigo PENAL}

El proyecto finalmente introduce siete modificaciones al Código Penal. Si bien el femicidio aparece como el núcleo de la regulación, la reforma es más integral. El examen se hará según el orden de los artículos que se mudan.

\subsubsection{Estado de necesidad general (art. $\left.10 N^{\circ} 11\right)$}

\section{a) Contexto}

El legislador aprovecha "paradójicamente" el derogado número 11 del artículo 10 , que contemplaba una eximente de responsabilidad penal para el marido que mataba o hería a su mujer y a su "cómplice" al sorprenderla infraganti en "delito de adulterio"14. El numeral que antes eximía de responsabilidad penal solo al marido, pues únicamente la mujer cometía adulterio (antiguo artículo 375) ${ }^{15}$,

14 Verdugo Marinkovic (1968) Código Penal (concordado, con jurisprudencia y doctrina), Ediciones Encina, Santiago, pp. 97-100.

15 De todas formas, se ha de tener presente que el delito de adulterio se derogó recién en 1994, mientras que la eximente para el marido que mataba a su mujer adúltera y a su cómplice se eliminó en 1953. 
hoy contempla una eximente que surge a propósito de amenazas y agresiones a la mujer por su marido o conviviente, sin importar si lo es actualmente o si lo fue.

La norma se introduce a propuesta del profesor Enrique Cury Urzúa ${ }^{16}$ a propósito de la discusión que se generó en el Congreso sobre la situación de "exigibilidad de otra conducta por parte de las mujeres maltratadas". En su intervención el destacado penalista señaló que la idea que intentó plasmar la Cámara de Diputados proviene del "estado de necesidad disculpante” del Código Penal alemán $\left(\$ 35^{17}\right)$, aunque la redacción final propuesta que es la que en definitiva se recoge la toma directamente del Código Penal suizo (Art. $34^{18}$ ) adecuándola a la redacción del Código

16 Ver: Informe de la Comisión Mixta, Boletines $\mathrm{N}^{\circ}$ 4.937-18 y 5.308-18, refundidos.

17 “\$ 35. Estado de necesidad disculpante (1) Quien en un peligro actual para la vida, el cuerpo o la libertad no evitable de otra manera, cometa un hecho antijurídico con el fin de evitar el peligro para él para un pariente o para otra persona allegada, actúa sin culpabilidad. Esto no rige en tanto que al autor se le pueda exigir tolerar el peligro, de acuerdo con las circunstancias particulares, porque el mismo ha causado el peligro o porque el estaba en una especial relación jurídica. Sin embargo, se puede disminuir la pena conforme al $\$ 49$ inciso 1 , cuando el autor no debería tolerar el peligro en consideración a una especial relación jurídica.

(2) Si el autor en la comisión del hecho supone erróneamente circunstancias que a él lo puedan exculpar conforme al inciso primero, entonces solo será castigado cuando el error hubiese podido evitarse. La pena ha de atenuarse conforme al $\$ 49$, inciso 1".

Señaló que una disposición similar se encuentra contenida en el artículo 54 del Código Penal italiano, que señala que "no es punible aquel que ha cometido el hecho por haber sido coaccionado a el por la necesidad de salvarse a si o a otro de un peligro actual, de un daño grave a su persona, peligro que no ha causado voluntariamente ni era de otra manera evitable, siempre que el hecho sea proporcionado al peligro".

18 Art. 34 Code Pénal Suisse (1942): Etat de nécessité_1. Lorsqu'un acte aura été commis pour préserver d'un danger imminent et imposible à détourner autrement un bien appartenant à l'auteur
Penal chileno, de manera que nos resultase familiar. En cualquier caso, la incorporación en la parte general tiene lugar para cualquier delito y sujeto, sin mayores especificaciones que los requisitos que establece esta eximente.

El nuevo numeral 11 dispone que están exentos de responsabilidad criminal: "El que obra para evitar un mal grave para su persona

de l'acte, notamment la vie, l'intégrité corporelle, la liberté, l'honneur, le patrimoine, cet acte ne sera pas punissable si le danger n'était pas imputable à une faute de son auteur et si, dans les circonstances où l'acte a été commis, le sacrifice du bien menacé ne pouvait être raisonnablement exigé de l'auteur de l'acte.

Si le danger était imputable à une faute de ce dernier ou si, dans les circonstances où l'acte a été commis, le sacrifice du bien menacé pouvait être raisonnablement exigé d l'auteur de l'acte, le juge atténuera librement la peine (art. 66).

2. Lorsqu'un acte aura été commis pour préserver d'un danger imminent et imposible à détourner autrement un bien appartenant à autrui, notamment la vie, l'intégrité corporelle, la liberté, l'honneur, le patrimoine, cet acte ne sera pas punissable. Si l'auteur pouvait se rendre compte que le sacrifice du bien menacé pouvait être raisonnablement exigé de celui auquel le bien appartenait, le juge atténuera librement la peine (art. 66)

(Estado de Necesidad: 1. Cuando un acto hubiere sido cometido para preservar un bien perteneciente al autor, de un peligro inminente e imposible de evitar de otra manera, especialmente la vida, la integridad corporal, la libertad, el honor y el patrimonio, este acto no será punible si el peligro no era imputable a una falta [culpa] de su autor y si bajo las circunstancias en que el acto fue cometido el sacrificio del bien amenazado no podía ser razonablemente exigido al autor del acto.

Si el peligro es imputable a una falta [culpa] de este último o si, en las circunstancias en que el acto fue cometido, el sacrificio del bien amenazado podía ser exigido del autor del acto, el juez atenuará libremente la pena (art. 66).

2. Cuando un acto hubiere sido cometido para preservar un bien perteneciente a otro de un peligro inminente e imposible de evitar de otra manera especialmente la vida, la integridad corporal, la libertad, el honor y el patrimonio, ese acto no será punible. Si el autor podía darse cuenta que el sacrificio del bien amenazado podía ser razonablemente exigido de aquel a quien pertenecía el bien, el juez atenuará libremente la pena (art. 66)). 
o derecho o los de un tercero, siempre que concurran las circunstancias siguientes:

$1^{a}$. Actualidad o inminencia del mal que se trata de evitar.

$2^{a}$. Que no exista otro medio practicable y menos perjudicial para evitarlo.

$3^{a}$. Que el mal causado no sea sustancialmente superior al que se evita.

$4^{a}$. Que el sacrificio del bien amenazado por el mal no pueda ser razonablemente exigido al que lo aparta de sí o, en su caso, a aquel de quien se lo aparta siempre que ello estuviese o pudiese estar en conocimiento del que actúa”.

\section{b) Características y fundamento}

La disposición establece una eximente de responsabilidad penal por causar un mal para evitar otro mal grave. La circunstancia especial es este "mal grave" actual o inminente para la persona o derecho de quien causa aquel otro mal "necesario" para impedirlo o para un tercero. El legislador habla en los mismos términos que utiliza para la legítima defensa (artículo $10 \mathrm{~N}^{\circ}$ s $\left.4-6\right)$ respecto del mal amenazado. Se trata de una situación de peligro en la que se enfrentan dos males para dos bienes y el mal causado es el único medio para evitar el mal amenazado: clásica idea del estado de necesidad $^{19}$.

La ley establece requisitos expresos para su procedencia como eximente, sin los límites del estado de necesidad justificante del $\mathrm{N}^{\circ} 7$ de este mismo artículo. El conflicto de intereses inherente al estado de necesidad excede aquí el ámbito de la justificación, al liberar de responsabilidad no solo en casos de que se causen males menores para evitar los mayores. No se exige una distinción de males semejante. Se pueden causar males iguales e incluso superiores -aunque no "sustancialmente"-, como en la legítima defensa ${ }^{20}$. La diferencia es

19 PolitofF; Ortiz (Directores); Matus (Coordinador) (2002): Texto y comentarios del Código Penal chileno, Santiago: Editorial Jurídica de Chile. T. I, pp. 140 y 141.

${ }^{20}$ El Derecho no hace diferencias entre bienes y males iguales y no puede valorar uno más que otro, autorizándolo. De allí que el estado de necesidad que en este estado de necesidad el mal que se trata de evitar no proviene de un agresor ilegítimo, que estaría obligado a soportar el mal causado y que explica la autorización o justificación del Derecho en la legítima defensa aunque el mal causado no sea menor al amenazado. En esta circunstancia se observa un interés preponderante, la preservación del derecho del injustamente agredido, con la pérdida de protección jurídica para el interés del injusto agresor (que debe cargar con el mal que se le causa), y la actuación del Derecho por la imposibilidad del Estado para intervenir en esta situación. El estado de necesidad que aquí se incorpora no se refiere al mal que se causa al ilegítimo agresor, sino que exime de responsabilidad incluso por causar males "no sustancialmente superiores" si se dan los requisitos que distinguen esta causa como un estado de necesidad general y exculpante. Así lo reconoce Cury expresamente en su intervención ante la Comisión Mixta: "no se presenta en el momento una agresión propiamente tal, sino que se configura ante un hecho o estado que pone a la persona en una situación en la que no le es exigible otra conducta" ${ }^{21}$.

No es, por tanto, un problema de injusto, o no es solo de injusto (caben también males menores y sin el límite al daño para la propiedad ajena). La conducta sigue siendo antijurídica para males mayores, pero se comprende la infracción de la norma por la especial circunstancia de peligro (mal grave para su

justificante, aunque no se limite solo a los daños para la propiedad, únicamente existe cuando procede una ponderación de males y se aplica como autorización del mal menor frente a uno mayor. Considera los bienes y sus formas de afectación y contempla la posibilidad de bienes iguales en caso del "estado de necesidad defensivo", cuando además hay una perturbación del orden jurídico. MIR Puig, Santiago (2008): Derecho penal. Parte general, $8^{\text {a }}$ ed., Barcelona: Editorial Reppertor, pp. 463 y 469 y 470 . Si no se hace esta diferencia, que se explica por la propia naturaleza de una y otra eximente, las circunstancias del art. $10 \mathrm{~N}^{\circ}$ s $4-6$ también serían superfluas.

${ }^{21}$ Informe de la Comisión Mixta, Boletines $\mathrm{N}^{\circ}$ 4.937-18 y 5.308-18, refundidos. 
persona o derecho o para un tercero) ${ }^{22}$, siempre que se den todos los demás elementos que completan el estado de necesidad.

El elemento esencial es el mal que se amenaza, pues es la situación de peligro que da origen al estado de necesidad, pero únicamente podrá servir para exculpar el daño provocado a otro si este es el único camino para evitar el mal amenazado. Así, Feuerbach ${ }^{23}$ lo sostuvo incluso para el hurto famélico: "cuando es la única posibilidad para la conservación de la vida del ladrón o de su mujer o de sus hijos". Si se afirma para eximir de responsabilidad en caso de males menores a bienes disponibles, con mayor razón procede para eximir de responsabilidad si se causan males mayores, aunque "no sustancialmente", a los que se busca evitar. El mismo Feuerbach ${ }^{24}$ alude a un estado de necesidad como categoría de inculpabilidad "en que, incluso con consciencia de la ley penal, estuviere anulado el posible efecto de la misma sobre el impulso"; contempla dos supuestos, uno que puede enmarcarse dentro

22 Silva SÁnCHEZ, Jesús-María (1982): “Sobre el estado de necesidad en Derecho penal”, ADPCP, T. XXXV, Fasc. III, pp. 663-691, p. 671, afirma precisamente que se justifica la amplitud de los males que se evitan en el estado de necesidad justificante frente a la legítima defensa porque en aquel estado "existe el importante margen de garantía de no causar un mal mayor al que se trata de evitar". Aunque se refiere al art. $8,7^{\circ}$ del antiguo CP. español, el argumento no cambia respecto del actual art. 20, $5^{\circ}$, ni ante nuestra nueva eximente del número 11 . Como se comparan males y el mal causado siempre es mayor en cuanto lesión y no peligro, introduce la idea de la trascendencia jurídico-social para la ponderación que importe la menor perturbación posible (pp. 665, 668 y 669). Esta misma idea suele describirse en el Derecho alemán desde los intereses en conflicto: en toda justificante se actúa conforme a Derecho cuando se da preferencia al interés más valioso frente al de menos valor. Ver RoXIN (1997) pp. 672-675.

23 Von Feuerbach, P. J. A. R. (1847): Tratado de Derecho penal común vigente en Alemania, Traducción de la $14^{a}$ edición alemana por Eugenio Raúl Zaffaroni; Irma Hagemeier, Hammurabi, Buenos Aires, 1999, \$321, pp. 220 y 221.

${ }^{24}$ VON FeUerbach (1847), \$ 91 pp. 104 y 105. de la locura (hecho cometido "estado de tribulación presente para el que la resistencia humana no estuviere normalmente desarrollada, siendo el único medio de alejarlo") y la necesidad cuando hay un peligro actual o inminente para la vida o para otro bien personal irreemplazable, con lo que se grafica la idea de "mal grave" para la persona o su derecho. En este caso, expresa que el hecho (dañoso) ha de ser el "único medio de salvación, sea que la persona se encuentre en este peligro por mero accidente o por la coerción antijurídica de otro (amenazas de hecho, vis compulsiva)". Incluye el caso de legítima defensa y estados de necesidad por otras fuentes de peligro, que no muestra claramente el tratamiento de este estado. Sí se desprende la exigencia que supone esta circunstancia para eximir de responsabilidad.

\section{c) Requisitos}

\section{i. Mal actual o inminente}

El elemento esencial es que exista un mal que se trata de evitar, que puede recaer sobre cualquier bien jurídico relativo a la persona o derecho de quien causa el mal necesario o de un tercero.

El mal debe ser real y puede ser actual, presente, o inminente, que se amenaza o está pronto a ocurrir. Como señala Roxin la actualidad del peligro en el estado de necesidad excluyente de responsabilidad comprende períodos de tiempo sustancialmente más grandes que la actualidad de la agresión en la legítima defensa, lo que rige sobre todo para el llamado peligro permanente, en que una situación que amenaza con un peligro se puede convertir en cualquier momento en un daño, sin que se pueda decir exactamente cuando ocurrirá tal cosa, precisamente un ejemplo de este peligro es el tirano familiar que de momento está pacífico, pero que en cualquier instante puede proceder a nuevos malos tratos ${ }^{25}$.

El mal amenazado puede tener cualquier fuente, salvo la agresión ilegítima de la propia "víctima", que sería un supuesto de jus-

25 Roxin, Claus (1997): Derecho penal. Parte general, traducción de la $2^{\text {a }}$ ed. Alemana y notas por LUZON PEÑA, Editorial Civitas, p. 903. 
tificación por legítima defensa, y que provenga de quien causa el mal que se busca eximir, pues habría provocado él mismo la circunstancia que lo "disculparía" por el mal causado a otro. En este caso, su provocación lo obligaría a cargar con el mal que crea, sin que proceda la circunstancia, como se desprende del $4^{\circ}$ requisito de la eximente.

El mal con que se amenaza no requiere ser mayor que el mal causado, pero sí debe ser "grave", en términos que explique la eximente. Así, puede ser superior al causado y en este caso configuraría una justificante, una autorización del mal menor causado para evitar uno mayor, más allá del estado de necesidad justificante del $\mathrm{N}^{\circ} 7$, según se verá en el siguiente requisito. Se comprende la amplitud de este mal que se trata de evitar con relación a la legítima defensa para la justificación por sus condiciones: no procede, como lo afirma Silva Sánchez ${ }^{26}$, si se causan males superiores y existen límites de proporcionalidad. La situación cambia cuando ese mal actual o inminente es igual al causado o, incluso, inferior. Habría una ponderación en contra del mal causado (aunque no sea sustancialmente superior) y la exención se explicaría por los demás requisitos de necesidad, en cuanto supongan una situación de inexigibilidad de otra conducta conforme a la norma. En todo caso, la gravedad del mal amenazado es una condición para que proceda la eximente, que explica la necesidad particularmente como "disculpante". Aquí tiene relevancia la consideración de este mal en el supuesto de necesidad de Feuerbach ${ }^{27}$ : "peligro actual e inminente para la vida o para otro bien personal irreemplazable". Si estamos fuera de las justificaciones, el mal que se trata de evitar ha de ser una perturbación de tal entidad que suponga una presión suficiente como para eximir de responsabilidad penal por la causación de un mal, aunque mayor, inexigible. Si este requisito falta no puede haber siquiera una atenuante, pues es la base de la eximente.

\footnotetext{
26 SilVA SÁNCHEZ (1982) pp. 671, 676 y ss.

27 VON FEUERBACH (1847) \$91 p. 104.
}

ii. Que no exista otro medio practicable y
menos perjudicial para evitarlo
El segundo requisito alude a los medios con los que el agente disponía para evitar el mal amenazado. No debe existir un medio menos lesivo practicable. Elemento negativo propio de un estado de necesidad, en los mismos términos en que se establece para el estado de necesidad justificante (artículo $10 \mathrm{n}^{\circ} 7$, requisito $3^{\circ}$ ) y que alude a la idea de racionalidad de la conducta realizada. Esta racionalidad también es coherente con el hecho de que el mal causado sea el único medio para salvar el bien amenazado del mal actual o inminente. Si existe otro medio menos gravoso y no se emplea ya no se está bajo una situación de necesidad que pueda eximir de responsabilidad. Podría aplicarse una circunstancia atenuante como eximente incompleta del artículo $11 \mathrm{~N}^{\circ} 1$.

\section{iii. Que el mal causado no sea sustancialmente superior al que se evita \\ El mal causado puede ser menor al mal} evitado, igual o incluso superior. Si es menor estaríamos frente a una hipótesis de estado de necesidad justificante, pues el Derecho puede autorizar la afectación de un mal menor para salvar uno mayor cuando no haya otro medio practicable menos perjudicial. A diferencia del estado de necesidad justificante del $\mathrm{N}^{\circ} 7$, aquí no hay límite para la clase de mal "necesario". Puede ser para cualquier bien protegido y su afectación no se restringe a los daños para que proceda la eximente. Con esto, pierde relevancia el tradicional estado justificante y se amplía a otros males ${ }^{28}$, si fueren menores al que se evita. Si el mal causado es igual o "algo" superior (no sustancialmente superior) al mal que se trata de evitar estaríamos frente a un estado de necesidad exculpante, en cuanto el

\footnotetext{
${ }^{28}$ Esta consecuencia fue señalada por Juan Domingo Acosta en su intervención ante la Comisión Mixta, señala que la eximente propuesta "abarca más de lo indicado en la referida causal séptima lo que, estimó, puede tornar superflua una norma sobre la cual existe amplia jurisprudencia y doctrina”. Informe de la Comisión Mixta, Boletines $\mathrm{N}^{\circ}$ 4.937-18 y 5.308-18, refundidos.
} 
Derecho no autoriza las afectaciones mayores ni distingue situaciones equivalentes jurídicamente, pero sí puede comprender conductas antijurídicas si la infracción de la norma no es exigible ante esas circunstancias de peligro. La exigencia debe ser de tal entidad que la libertad se limite, de suerte que el agente no tenga deliberación, no pueda decidir acerca del cumplimiento de lo ordenado.

Aunque el mal causado sea superior el que no lo sea sustancialmente señala un límite para la comparación de males, adicional a la gravedad del mal que se amenaza. La ponderación de males que supone todo estado de necesidad debe hacerse conforme al objeto de las normas que entran en conflicto. Aquí resulta elemental, junto con el fundamento de la necesidad como único camino, tener presente la dignidad humana como criterio que impida utilizar como objeto al individuo y sus derechos fundamentales. Así lo afirma Mir Puig 29 incluso si el mal causado es menor. Entiende que la diferencia de bienes y males es insuficiente aun para la justificación, si ella es mínima "resulta político-criminalmente excesivo que el Derecho apruebe sin más la perturbación del orden jurídico y, en su caso, la intromisión en derechos ajenos". También considera excesivo exculpar si el bien amenazado no es personalísimo y no afecta la normal motivación del sujeto, que se condice con la declaración citada de Feuerbach. Solo "merece quedar impune" una conducta cuando su evitación -el cumplimiento de la norma- supondría una conducta heroica, que únicamente se da si peligran bienes personales. Este es un parámetro de gravedad que se ha de tener en cuenta ${ }^{30}$. Si

${ }^{29}$ Mir PUIG (2008) pp. 471 y 472. Critica especialmente la amplitud del estado de necesidad espanol frente al auxilio de terceros, sin exigir una vinculación personal que permita compartir la "situación de conflicto psicológico del necesitado".

${ }^{30}$ NOVOA pretende desatacar semejante idea de necesidad que impida la imputación personal, pues su omisión supondría "exigir al ser humano común una capacidad de sacrificio y renunciamiento enteramente excepcional, o imponerle un heroísmo que la norma jurídica, por su propia naturaleza, no está facultada para exigir", pero no limita sus consideraciones. Lo concibe como causa de exculpación incluso cuan- el mal que se evita en las circunstancias del caso no genera una presión suficiente como para determinar la inexigibilidad de la norma, solo deberá aceptarse una atenuante, conforme los términos del artículo $11 \mathrm{~N}^{\circ} 1$.

Pacheco $^{31}$, comentando el estado de necesidad justificante, advierte el peligro que supondría dejar este estado en la culpabilidad cuando no se limitan los requisitos del mal menor y del medio menos perjudicial practicable y sus efectos. "La razón no puede encontrar justo que se cause un mal de gran tamaño para impedir otro que sea menor; la razón no puede permitir que se acuda a esos aventurados remedios, en tanto que existan otros posibles, menos aventurados, menos perjudiciales. En el primer caso falta la utilidad; en el segundo, la necesidad de lo que como recurso se intenta”. Señala que en ambos casos es ilegítimo y no exime de responsabilidad por el mal causado. Reconoce que la consideración de estos requisitos es difícil y que los tribunales han de apreciar prudencialmente las circunstancia del hecho, pero le tranquiliza que el debate no se centre en la "inculpabilidad o culpabilidad absoluta" porque la ley regula los efectos si no

do el agente "haya decidido serenamente" destruir un bien y no restringe el peligro a los bienes personales. Señala que la causa existe "desde que a ningún individuo podría reclamarse una conducta que permitiera la destrucción de su propio bien”. Podría interpretarse como aquellos personales, de los que depende su existencia -vida y salud-, pero la redacción no es determinante. NOVOA MONREAL, Eduardo (2005) Curso de Derecho penal chileno, parte general, $3^{\text {a }}$ ed., Editorial Jurídica de Chile, Santiago, t. I., pp. 560 y 561.

31 La Comisión Redactora de nuestro CP. (Sesión 121) se pronuncia en este sentido frente a una indicación del Sr. Fabres para eximir también por causar daños a las personas: "teniendo en cuenta que sería peligroso autorizar los daños graves que pudiera inferirse a las personas al amparo de esta disposición, y que en cuanto a daños leves no vale la pena de consignar una disposición que rara vez tendría aplicación y que se prestaría a abusos”. En este sentido, resulta interesante la advertencia de FINNIS (1997) p. 226, en cuanto "un sistema jurídico decente excluye incondicionalmente la occisión o el daño de personas inocentes como medio para cualquier fin, ya sea público o privado". 
concurre alguno de estos elementos, como atenuantes. Expresa que sin este correctivo la solución sería peligrosa "y la arbitrariedad de los jueces verdaderamente inmensa". No ocurre así cuando existen requisitos expresos, pero sí, y como es lógico, su consideración se deja a la apreciación prudencial de los juzgadores para decidir sobre la responsabilidad del agente.

iv. Que el sacrificio del bien amenazado por el mal no pueda ser razonablemente exigido al que lo aparta de si o, en su caso, a aquel de quien se lo aparta siempre que ello estuviese o pudiese estar en conocimiento del que actúa

Este último requisito se explica por el motivo de la eximente, la existencia de un peligro actual o inminente que haga procedente la eximente. Para que el mal causado no genere responsabilidad penal se requiere que no sea exigible para el agente soportar el mal amenazado o que no lo sea para el tercero amenazado, siempre que esta última circunstancia sea conocida por el que actúa. Apunta a la obligación del autor de soportar el mal que se trata de evitar o de no intervenir si el tercero debe soportarlo. No alude a la falta de provocación de quien causa el mal, pero excluye el hecho si este sujeto es el mismo que origina el mal amenazado.

Se pierde la eximente si la circunstancia, el peligro actual o inminente que se trata de evitar, es creado por el mismo que causa un mal a otro. Este debe cargar con las consecuencias del peligro que él crea o provoca. También se incluyen males cuya producción está autorizada por el derecho, como la detención en caso de flagrancia o la privación de libertad como pena. En el mismo sentido, se contempla la situación de sujetos que por su profesión u oficio deben soportar riesgos como la Policía o los bomberos ${ }^{32}$. Estos dos últimos

\footnotetext{
32 Aquí ya cabe recordar las palabras de Cousiño (1979) pp. 419 y 429 que rechazaba el estado de necesidad para los bomberos respecto de su "actividad protectora" incluso frente a riesgos para su propia vida. PACHeCO, Joaquín Francisco (1881): El Código Penal concordado y comentado, $5^{\mathrm{a}}$ ed., Imprenta y Fundición Manuel Tello, Madrid, p. 163
}

supuestos se expresan de modo más sencillo en el CP. español para el estado de necesidad justificante: 3. "Que la situación de necesidad no haya sido provocada intencionalmente por el sujeto" y 4. "Que el necesitado no tenga, por su oficio o cargo, obligación de sacrificarse". Si el que causa el mal o el tercero está obligado a cargar con el mal amenazado no se exime por el causado. Básicamente y como en la legítima defensa, se trata de excluir hipótesis de agresores injustos que deben soportar el mal, pero también aquellos casos en los que el mal amenazado está legítimamente inferido si el sujeto por su función, cargo o posición debe soportar riesgos, como las aprensiones de funcionarios policiales en el cumplimiento de su deber.

Si falta alguno de estos elementos, salvo el primero, se configura una atenuante que puede ser muy privilegiada, si se dan los supuestos del art. 72 de CP., plenamente aplicable a la especie, toda vez que se trata de una nueva causal de exención de responsabilidad penal con requisitos enumerados.

\subsubsection{Elemento de la violación (art. $\left.361,2^{\circ}\right)$}

Se reemplaza el $2^{\circ}$ supuesto de violación del artículo 361, cuando la víctima estuviere privada de razón o se aprovecha su incapacidad "para oponer resistencia". Se modifica esta última indicación "para oponer resistencia" por "para oponerse".

Debe destacarse la importancia de esta reforma, que viene a ratificar como elemento esencial de la violación la falta de consentimiento de la víctima, dejando de lado cualquier referencia a una posible resistencia de la víctima, elemento que era requerido por parte de la doctrina tratándose de la violación con fuerza, precisamente por la alusión que se hacía a la misma en el numeral segundo del artículo 361 del C.P.

La exigencia de resistencia en la víctima era criticada por la doctrina más autorizada sobre la materia, en la convicción de que lo verdaderamente importante es la actitud violentista del sujeto activo más que la fuerza opositora de la víctima. En el mismo sentido se señalaba que semejante reclamo significaba 
incorporar un elemento que no era exigido por el tipo penal, así como incrementar el riesgo para la integridad corporal o, incluso, la vida de la víctima ${ }^{33}$.

Por otro lado, la nueva redacción del tipo penal parece permitir una interpretación amplia respecto de la imposibilidad de oposición de la víctima, permitiendo incluir hipótesis, que ya algunas sentencias habían recogido, como los casos de violaciones o abusos sexuales en su caso, realizados de manera sorpresiva para la víctima ${ }^{34}$. En el mismo sentido, podrían incluirse en esta modalidad aquellos casos de imposibilidad psicológica de la víctima para oponerse a la violación, como supuestos en que se da el síndrome de acomodación en el abuso sexual ${ }^{35}$.

\subsubsection{Agravantes en los delitos sexuales} (intercala nuevo art. 368 bis)

Se intercala un nuevo artículo 368 bis, de modo que el anterior pasa a ser 368 ter. La nueva disposición hace procedente la alevosía y la pluralidad de autores en los delitos sexuales: Artículo 368 bis. "Sin perjuicio de lo dispuesto en el artículo 63, en los delitos señalados en los párrafos 5 y 6 de este Título, serán circunstancias agravantes las siguientes:

$1^{\circ}$ La $1^{\text {a }}$ del artículo 12 .

20 Ser dos o más los autores del delito".

Lo interesante de esta modificación es que hace procedente en los delitos sexuales una agravante como la alevosía que antes se

33 Rodríguez Collao, Luis (2001): Delitos Sexuales, Editorial Jurídica de Chile, Santiago, pp. $147-150$

34 Sentencia Tribunal Oral en lo Penal de Calama RUC 0600188547-0 y Sentencia Juzgado de Garantía de Antofagasta $\mathrm{RUCN}^{\circ} 0600175675-1$

35 El síndrome ha sido descrito por Ronald Summit, M.D. y está compuesto por cinco categorías (1) el secreto, (2) el desamparo, (3) el entrampamiento y acomodación, (4) la revelación tardía y no convincente, $494 \mathrm{~N}^{\circ} 5$ y (5) la retractación. Una interpretación amplia que incluya hipótesis de imposibilidad física o síquica de la víctima se ha aceptado incluso con la redacción original, véase Garrido Montt, Mario (2002): Derecho Penal, Tomo III Parte Especial, Editorial Jurídica de Chile, Santiago, p. 364. rechazaba por expresa disposición legal, al disponer el art. 12 No 1 del C.P. su aplicación solo a los delitos contra las personas ${ }^{36}$. De todas formas, se mantiene el límite del artículo 63 , que impide considerarla cuando ella es inherente al delito, como suele ocurrir.

Tratándose de la nueva agravante de ser dos o más los autores, cabe señalar que los vocablos utilizados por la norma no deberían dar lugar a discusión respecto a si son o no necesarios antecedentes previos de los autores para que se configure la agravante, no ocurre lo mismo a propósito de una agravante similar contemplada en los delitos de robo en que se utiliza la expresión "malhechores".

La alusión que se hace a los autores, parece hacerse en sentido genérico, respecto de aquellos sujetos que participan materialmente del delito sexual ya sea ejecutándolo o presenciándolo, aumentando con ello la indefensión de la víctima, de manera que sería aplicable aún para individuos que revistan incluso la calidad de partícipes, siempre y cuando se den las circunstancias señaladas.

Por otro lado, la nueva circunstancia modificatoria ha de tener como fundamento, al igual que el robo, una mayor indefensión de la víctima al actuar en grupo, de esta manera en un gran número de casos no será procedente la aplicación de ambas agravantes en conjunto por vulneración al principio del non bis in idem recogido en el art. 63 de nuestro Código Penal. Podría entenderse que ambas circunstancias son inherentes a varios de los delitos sexuales, lo que impediría su consideración para aumentar la pena.

\subsubsection{Procedimiento por violación a cónyuge o conviviente (art. 369,4) \\ Se reemplaza el inciso $4^{\circ}$ del artículo} 369 por el siguiente: "En caso de que un cónyuge o conviviente cometa alguno de los deli-

36 No obstante esta restricción, algunos fallos se han pronunciado a favor de la agravante tratándose de estos delitos. Entre otras, la sentencia Tribunal Oral en lo Penal de Villarrica RUC 0300170078-1, ratificada por la I. Corte de Apelaciones de Temuco Rol No 121-2004 y Sentencia Tribunal Oral en lo Penal de Villarrica RUC No 0400218443-0 
tos establecidos en los párrafos 5 y 6 de este Título en contra de aquel con quien hace vida común, se podrá poner término al proceso a requerimiento del ofendido, a menos que el juez, por motivos fundados, no acepte". La antigua redacción de la norma efectuaba un distingo entre las modalidades comisivas de la violación, permitiendo que en las hipótesis de los numerales 2 y 3 (privación de sentido, aprovechamiento de la incapacidad de la víctima y abuso de la enajenación o trastorno mental de la misma) no se diera curso al procedimiento o se dictara sobreseimiento definitivo, salvo que por la gravedad de la ofensa infligida la imposición o ejecución de la pena fuere necesaria; en cambio, si el ofendido lo requería se podía poder término al procedimiento cualquiera fuese la hipótesis de violación, a menos que el juez no lo aceptase por motivos fundados.

La distinción señalada hacía que en la práctica solo se diera lugar a investigaciones penales en los casos de uso de fuerza o intimidación. Hoy día las tres hipótesis de violación tienen el mismo tratamiento y siempre deben dar lugar a una investigación y juzgamiento, a menos que el ofendido quiera terminar el procedimiento y, en este caso, siempre que el tribunal acepte, lo que creemos no debería ocurrir si existen antecedentes de violencia intrafamiliar. La modificación refleja el interés público en que estos procesos sigan su curso.

2.1.5. Pérdida de facultades por violación de pariente menor (art. 370 bis)

El artículo 370 bis se refiere a las sanciones civiles que lleva aparejada la condena penal en materia de delitos sexuales. La ley agrega en el inciso primero de este artículo, como oración final la siguiente: "Además, si el condenado es una de las personas llamadas por ley a dar su autorización para que la víctima salga del país, se prescindirá en lo sucesivo de aquella”.

Debe destacarse la utilidad práctica de esta modificación, toda vez que hasta ahora los padres condenados por delitos sexuales contra sus hijos/as, no obstante perder todos los derechos civiles respecto de los mismos, debían otorgar su autorización para que los menores salieran del país, lo que claramente no concordaba con el espíritu de la norma que regulaba los efectos civiles de estos delitos. La nueva ley corrige esta inconsistencia.

\subsection{6. "Femicidio" (art. 390)}

Las modificaciones relativas al femicidio se introducen en el delito de parricidio. En primer lugar, se amplían los sujetos de este delito a los ex cónyuges y ex convivientes que ahora se sancionan con la pena del parricidio. Así, en el inciso primero del artículo 390 se reemplaza la expresión "a su cónyuge o conviviente" por "a quien es o ha sido su cónyuge o su conviviente". Con ello se agrava sustancialmente la responsabilidad penal de quienes fueron cónyuges o convivientes y sin límite de tiempo, pues ya no procede su imputación por homicidio simple sino como parricidas, que conlleva la pena más alta del Código Penal (presidio perpetuo calificado) ${ }^{37}$. La ampliación no se limita a los varones que matan a sus ex cónyuges o convivientes mujeres. Incluye a los ex cónyuges y ex convivientes hombres y mujeres. Desde esta perspectiva, se mantienen garantías constitucionales de igualdad ante la ley. Claro que, en realidad, solo será "parricidio" 38 si la víctima es varón, pues si es mujer pasa a ser "femicidio".

La segunda modificación alude a la incorporación del femicidio, al sumar un nuevo

\footnotetext{
37 Esta ley pretende mantener coherencia con los sujetos que concibe como "familia" la ley de violencia intrafamiliar, va más allá del vínculo conyugal. Aunque omite incluir a los padres de un hijo común y tampoco reforma la circunstancia mixta de parentesco del art. 13 (ni siquiera agrega al conviviente).

38 Cabe hacer notar que el término "parricidio" (paricidium), aunque surge en Roma para designar al homicidio doloso, como crimen dirigido a la comunidad que encabeza el pater-familias, se "limitó" al asesinato de los parientes a fines de la República. Pompeyo en una ley especial describe a los parientes, donde incluye incluso a los hermanos y hermanas, a los tíos y tías y al "patrono" y a la "patrona". Mommsen, Teodoro (1999) Derecho penal romano, $2^{a}$ ed. (Temis, Santa Fe de Bogotá) pp. 388-391, 405 y 406 .
} 
inciso segundo: "Si la víctima del delito descrito en el inciso precedente es o ha sido la cónyuge o conviviente de su autor, el delito tendrá el nombre de femicidio". Se reconoce la especial condición de mujer en el caso de homicidios por sus cónyuges o convivientes actuales o pasados, sin límite de tiempo. La incorporación se explica por la especial connotación que tiene el homicidio de mujeres por quienes son o han sido sus compañeros, es decir, el entorno familiar que agrava la conducta del agente "conocido", "familiar". Son dos circunstancias graves que se consideran, el contexto intrafamiliar y la condición de mujer. Se ha de tener especialmente presente la "lógica de la agravante o la calificante" al incorporar los ex compañeros (y compañeras) sin límite de tiempo. ¿Procederá aplicar la máxima sanción si, por ejemplo, se convivió con alguien por un mes y luego de cinco años se le da muerte? De nuevo se dejan muchas consideraciones al juzgador, que ha de tener en cuenta qué explica que la sanción establecida para la conducta homicida no sea suficiente, y haya de aplicarse una más fuerte o dura. La lógica de la agravante o de la calificante, según se trate de una circunstancia genérica o el propio legislador la incluya al establecer la pena -como en este caso- está en el estado de mayor indefensión en el que se halla la víctima de una agresión por parte de un pariente con el que está vinculado; donde existe conocimiento, confianza, "cariño"... Por ello, la víctima está en una posición de mayor debilidad, con menos posibilidades de repeler la ofensa, lo que denota la particular gravedad de la conducta. No es lo mismo un ex conviviente con el que no se tuvo hijos ni se mantuvo contacto por años, que otro con el que sí se da una o ambas circunstancias. Mir Puig ${ }^{39}$ destaca esta idea como fundamento que recoge el Tribunal Supremo español para no considerar la agravante del parentesco (artículo 23 del CP. español), que exige que "no haya perdido su significado de vinculación entre los parientes". La redacción de la norma española favorece este fundamento porque incorpora una idea de "vinculación".

${ }^{39}$ Mir PUIG (2008) pp. 635 y 636.
La consideración de la víctima mujer por el hecho de ser tal también denota una especial apreciación que puede importar el aumento de pena si el agente se vale de su condición de mujer para reducir sus posibilidades de defensa sin que sea necesario para la consumación del delito. Así, el término "femicidio" destaca esta calidad para el homicidio que se castiga con la mayor pena del Código Penal, aunque no hace distinción de pena si la víctima es el cónyuge o conviviente varón, actual o pasado. Desde esta perspectiva, hubiera sido deseable admitir el nombre "femicidio" para todo homicidio de mujer por el solo hecho de ser tal (femicidios no íntimos), sin que, por supuesto, esté incorporado en el parricidio que castiga en caso de relaciones familiares. La mayor gravedad puede igualmente reflejarse en una pena más dura por el artículo 12 No 6 (abusar de la superioridad del sexo o fuerzas) o por el artículo 12 No 18 (con ofensa o desprecio del respeto que merece el ofendido por su dignidad, autoridad, edad o sexo).

Por otra parte, la sanción por femicidio no supone limitarse necesariamente a la acción de varones hacia mujeres con las que están o hayan estado relacionados. La palabra cónyuge restringe a los varones, no así el término conviviente. Si bien la convivencia se considera o interpreta con las mismas calidades que la relación conyugal en cuanto permanencia, afectividad y entidad de la relación, no ocurre lo mismo con la diferencia entre hombre y mujer ${ }^{40}$. La relación de convivencia no supone por esencia, como lo hace el matrimonio, una relación entre un hombre y una mujer. De modo que puede ser sancionada como femicida una mujer que mate a su conviviente mujer actual o pasada.

\subsubsection{Limitación a excusa legal absolutoria (art. 489,2)}

La excusa legal que absuelve la responsabilidad penal de parientes en caso de come-

40 Así se ha sostenido que ella supone "cohabitación entre personas unidas por un vínculo afectivo y que goza de cierta estabilidad, sin importar el sexo de sus integrantes", SCA de La Serena, 8/1/2007, Rol: 373-2006. 
ter determinados delitos menores (hurto, defraudaciones y daños), por los mayores perjuicios que traería iniciar la persecución penal de los mismos en estos casos, se limita para el delito de daños entre cónyuges. Se intercala en el inciso segundo del artículo 489, a continuación de la palabra "delito", la frase: "ni tampoco entre cónyuges cuando se trate de los delitos de daños indicados en el párrafo anterior". Con esto, se limita la procedencia de la excusa legal absolutoria entre cónyuges si alguno comete delito de daños. Ya no se sostienen las razones de política criminal en estos supuestos y se establece como necesaria la respuesta penal si se determina la existencia de esta clase de delitos. No se incluye el caso de los convivientes, ya que respecto de ellos no rige la excusa legal absolutoria de acuerdo al tenor literal del art. 489 del CP.

\subsection{MODIFICACIONES A LA LEY N $\mathrm{N}^{\circ} 20.066$ SOBRE VIOLENCIA INTRAFAMILIAR}

Las modificaciones que siguen tienen especialmente en cuenta la idea de control y prevención de conductas violentas en el ámbito de la familia. Aunque no se restringen a la situación de la mujer agredida, son las conductas violentas que se dirigen en su contra las más comunes y, por tanto, las que se van a alcanzar con más fuerza por las indicaciones que siguen.

\subsubsection{Situación de riesgo (art. 7,2)}

Se agrega en el inciso segundo del artículo $7^{\circ}$, a continuación del punto aparte (.) que pasa a ser seguido, el siguiente párrafo:

"Asimismo, se presumirá que hay una situación de riesgo inminente, cuando el denunciado oponga, de manera violenta, su negativa a aceptar el término de una relación afectiva que ha mantenido recientemente con la víctima”.

\subsubsection{Medidas accesorias (art. 9)}

Se suma una medida accesoria de control y se aumentan los plazos máximos para todas. Se modifica el artículo 9 que contempla esas medidas en el sentido que sigue. En el inciso primero se agrega: "e) Obligación de presentarse regularmente ante la unidad poli- cial que determine el juez". También se reemplaza en el inciso segundo las palabras "un año" por "dos años".

\subsubsection{Regla la irreprochable conducta anterior en caso de delitos constitutivos de violencia intrafamiliar (art. 14 bis) \\ Se intercala el siguiente artículo 14 bis:} "En los delitos constitutivos de violencia intrafamiliar, el juez, para efectos de evaluar la irreprochable conducta anterior del imputado, deberá considerar las anotaciones que consten en el registro a que se refiere el artículo 12 de esta ley".

Con esta modificación se limita la procedencia de la atenuante de irreprochable conducta anterior y, de paso, se reconoce el contexto de violencia intrafamiliar al dar relevancia a conductas de esta clase que no llegan a configurar un delito por la consideración de las anotaciones en el Registro Especial de condenas por violencia intrafamiliar y medidas accesorias que se lleva en el Registro Civil.

\subsubsection{Plazo de medidas accesorias (art.} 16,2 y art. 9,2 b).

Al igual que en las medidas accesorias del artículo 9, se amplía el plazo de las medidas del artículo 16, en el inciso segundo: Cambia "un año" por "dos años". De nuevo, aparece la idea de prevención de conductas violentas que puedan llegar a lesionar la vida o integridad corporal de parientes.

\subsection{MODIFICACIONES PROCEDIMENTALES "CAUTELARES" \\ Por último, el legislador se preocupa} por la aplicación de las medidas cautelares para la mujer agredida, aunque no se limitan a su consideración. Ello ocurre especialmente cuando los Tribunales de Familia remiten el caso a la justicia penal. La ley agrega dos incisos al artículo 90 de la Ley No 19.968, que creó los Tribunales de Familia, aunque la redacción original motivó el pronunciamiento del Tribunal Constitucional por los alcances orgánicos de la nueva disposición:

"Previo a remitir una causa al Ministerio Público, el juez de familia adoptará las medidas cautelares que correspondan, las que se 
mantendrán vigentes en tanto el fiscal no decrete $o$ solicite su modificación o cese.

Si se plantea una contienda de competencia relacionada a un asunto de violencia intrafamiliar entre un juez de familia y el Ministerio Público o un juez de garantía, el juez de familia involucrado podrá adoptar las medidas cautelares que sean procedentes, las que se mantendrán vigentes hasta que la contienda de competencia sea resuelta".
El Tribunal cuestionó las "facultades" que se expresan para los fiscales. Así, en resolución de 18 de noviembre de 2010, Rol 1848-10-CPR., declaró inconstitucional la referencia a la posibilidad de decretar medidas cautelares y ordena la supresión de las palabras "decrete o". De modo que las medidas que ordene el Tribunal de Familia se mantendrán vigentes hasta que el fiscal simplemente solicite su modificación o cese. 
